\title{
New specmen design for studying the growth of small fatigue cracks with surface acoustic waves
}

\author{
Blair London \\ Office of Naval Research, Fellow and Research Assistant, Department of Materials Science and Engineering, \\ Stanford University, Stanford, California 94305
}

\begin{abstract}
The study of small surface fatigue cracks in AISI 4140 quenched and tempered steel by a nondestructive surface acoustic wave technique is summarized. A novel cantilevered bending, plate-type fatigue specimen is described that is compatible with the acoustic method. Small cracks are initiated from a $25-\mu \mathrm{m}$ deep surface pit produced by an electrospark machine. The importance of studying these cracks which closely approximate naturally occurring fatigue cracks is briefly discussed.
\end{abstract}

\section{HTRODUCTIOA}

The study of the growth behavior of small surface fatigue cracks has taken a major role in the fatigue literature within the past decade. The anomalous behavior of microcrack growth compared to the well-documented, more predictable growth of large cracks was described nearly $10 \mathrm{yr}$ ago by Pearson. ${ }^{1}$ These small cracks were shown to grow at a rapid rate below the long crack threshold stress intensity factor range $\left(\Delta K_{t h}\right)$ as shown in Fig. 1 . Since that time research has concentrated on the various metallurgical, ${ }^{2-7}$ mechanical, ${ }^{8-13}$ and environmental ${ }^{14,15}$ factors responsible for this small crack effect. Several excellent review articles ${ }^{16-18}$ have recently been published.

The most common way to monitor the growth of small surface cracks is to measure the increase in crack length at the surface caused by fatigue cycles. However, crack propagation into the load bearing section of the material, that is, in depth, is much more critical. Unfortunately, it is not directly possible to measure crack growth in depth by examining the surface. If the crack aspect ratio $a / c$, where $a$ is the crack depth and $c$ is half the surface length, is known then surface growth can be related to growth in depth, but this ratio is rarely known for a small growing fatigue crack.

A nondestructive technique using ultrasonic surface acoustic waves (SAW) has recently been developed by Resch et al., ${ }^{19-21}$ and applied to the study of small surface cracks. Based on the acoustic scattering theory of Kino ${ }^{22}$ and Auld, ${ }^{23}$ the technique uses the reflection of surface waves from the crack to predict the crack depth and monitor crack growth on the surface and in depth. The purpose of the present work is to describe a suitable sample design compatible with the acoustic method and satisfying experimental requirements specific to the study of small cracks.

\section{EXPERTMENTAL PROCEDURES}

The major components of the surface acoustic wave system are shown in Fig. 2. A 3-MHz sine wave pulse of three wavelengths duration is amplified to a zero-to-peak amplitude of $10 \mathrm{~V}$. The pulse is then input to the sending transducer. The transducer consists of a thin slice of $\mathrm{PZT}$ piezoe- lectric crystal embedded in a RTV silicone wedge which is cast into a mounting block. The entire transducer measures $13 \times 12 \times 11 \mathrm{~mm}$. The coupling medium between the transducer and the sample is a small amount of low viscosity diagnostic medical ultrasonic couplant spread on the bottom of the silicone wedge. The PZT crystal is positioned at the proper angle so that the longitudinal wave launched through the RTV silicone will produce a surface (Rayleigh) wave on

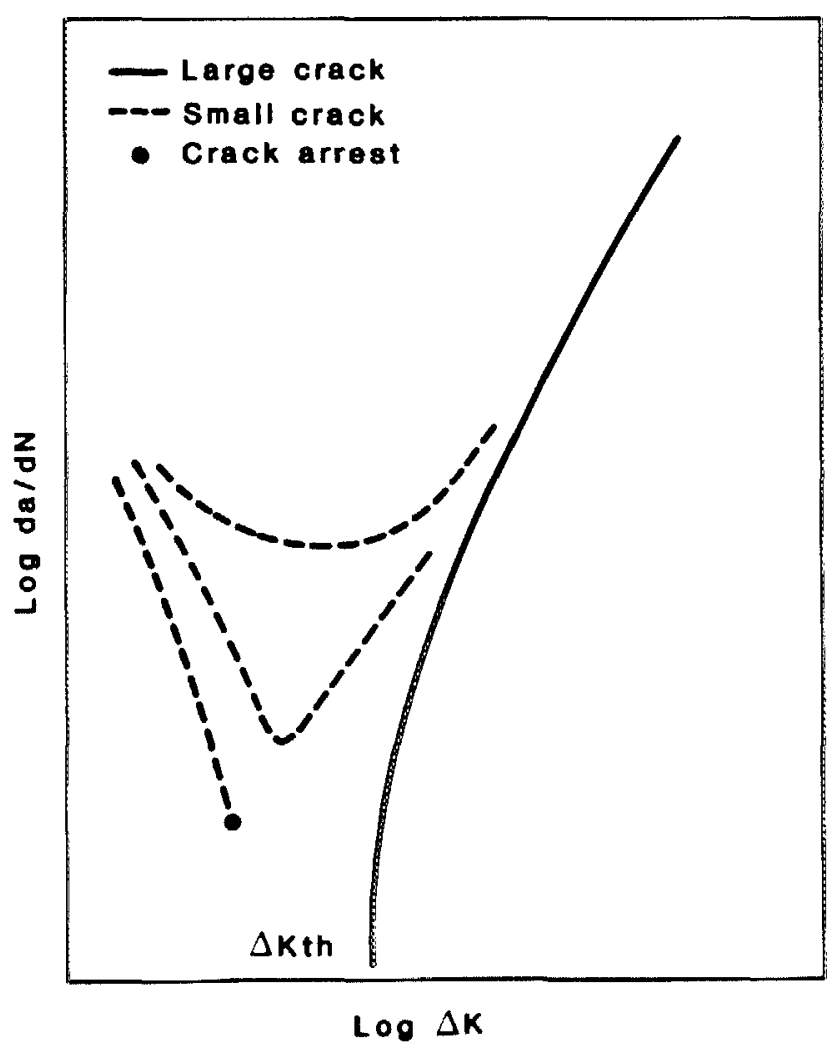

Fig. 1. The standard way to present fatigue crack growth data is to correlate the growth rate $d a / d N$, where $a$ is the crack depth and $N$ is the number of fatigue cycles, with the stress intensity factor range $\Delta K$. Long through cracks follow a fairly predictable line. These cracks will not propagate below the threshold stress intensity factor range $\Delta K_{t h}$. Small surface partthrough cracks may show anomalous growth behavior by propagating very rapidly below $\Delta K_{t h}$. 


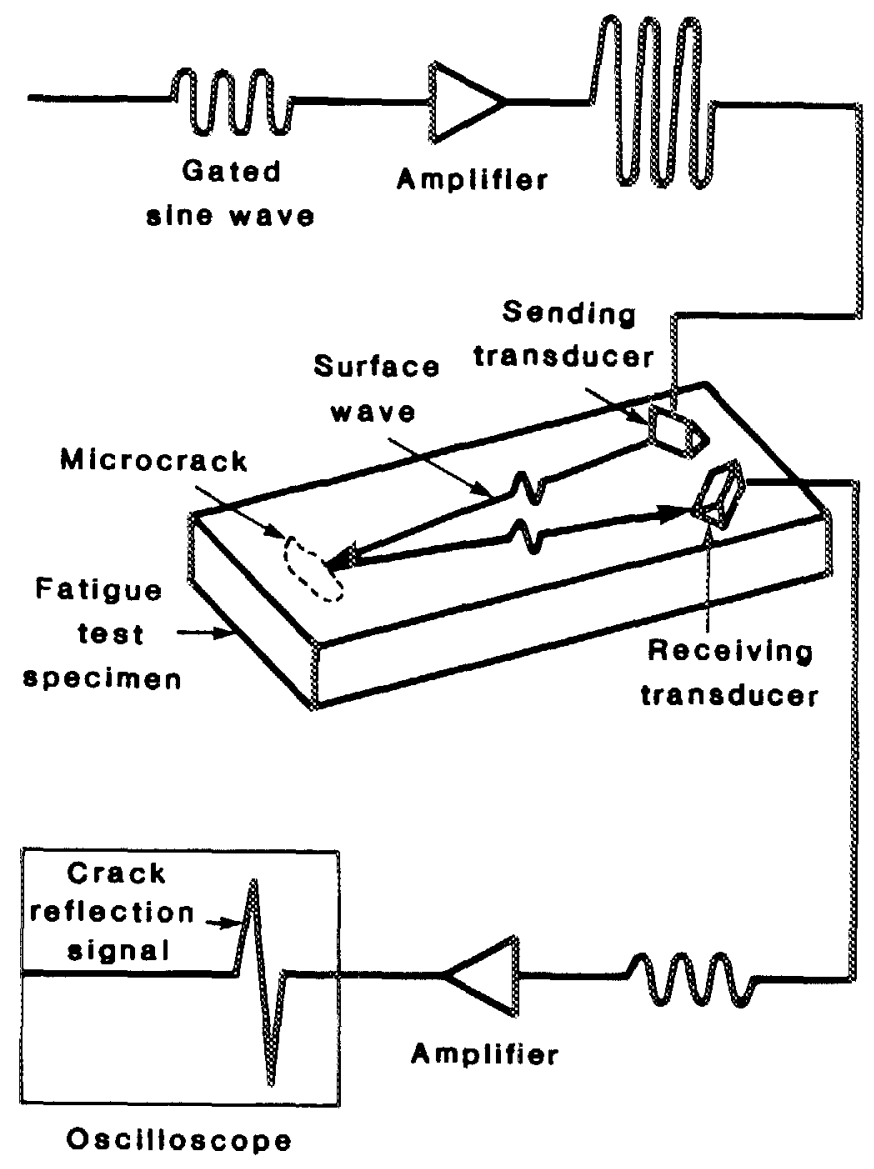

Fig. 2. Schematic diagram of surface acoustic wave system to monitor the growth of small surface fatigue cracks.

the specimen. The Rayleigh wave packet travels on the specimen surface in a directed, narrow beam approximately $4 \mathrm{~mm}$ in width with a slight amount of beam spreading. A crack in the acoustic path will cause the beam to reffect back to the receiving transducer. The reflected signal is then amplified and the output is monitored on an oscilloscope. The amplitude of the reflected signal is usually between $0.1-1.0 \mathrm{~V}$, depending on the size of the crack.

The details of this acoustic technique are explained adequately in Refs. 19-21, but several key points should be mentioned here. Small surface cracks may be tightly closed when the sample is not under an applied stress. Thus, to obtain a reflection from a crack, a remote tensile stress generally must be applied to cause the crack faces to part. Examining cracks in steel, the acoustic technique can gather quantitative information for crack depths greater than $50 \mu \mathrm{m}$, limited by the "noise" level inherent in the experimental system, up to $160 \mu \mathrm{m}$, representing the upper limit of validity of the acoustic scattering theory for a frequency of $3 \mathrm{MHz}$. Currently, a major limitation of the acoustic technique is that only one isolated fatigue crack can be examined. Multiple reflections from several surface cracks could create complicated interference patterns which the present theory cannot treat. Finally, it should be noted that the transducers are attached to the sample, using a simple c-clamp device which fits around the specimen, throughout the fatigue test so that in-situ crack growth can be monitored.

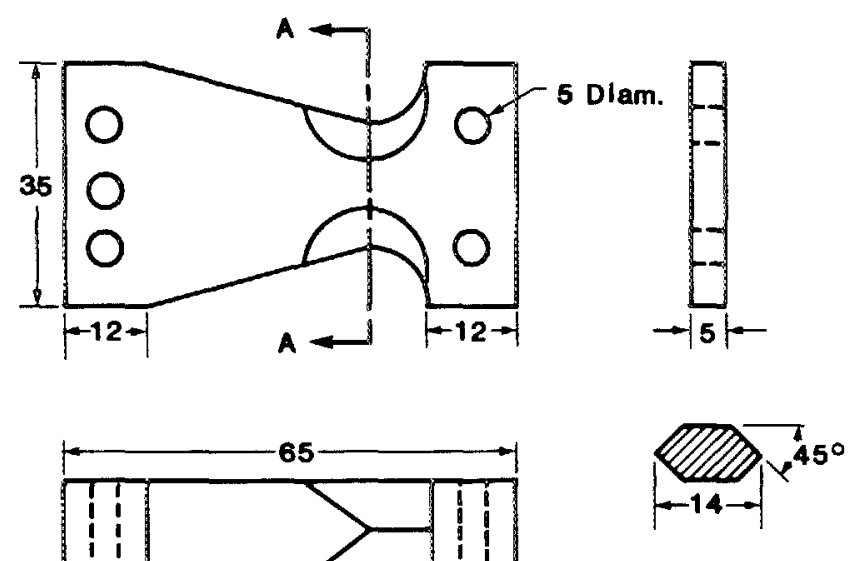

Section A-A

FIG. 3. Cantilevered bending fatigue specimen. The crack initiation pit is located on the center of the flat surface of section A-A. All dimensions are in millimeters.

AISI 4140 steel was used for the present study. The steel was specially processed, including vacuum degassing and calcium treatment, to ensure a minimal level of impurities in the final product. The samples were austenitized at $850^{\circ} \mathrm{C}$ for $1 \mathrm{~h}$ (in vacuum), oil quenched, tempered at $400^{\circ} \mathrm{C}$ for $1 \mathrm{~h}$ (in vacuum), and furnace cooled. The yield strength was approximately $1280 \mathrm{MPa}(185 \mathrm{ksi})$.

\section{A. Sample design}

Before experimental work on acoustically monitoring the growth of small fatigue cracks could begin, an appropriate sample design had to be developed. This design needed to satisfy the following requirements. First, the sample had to be compatible with surface acoustic waves. This requires a flat, polished surface and a thickness greater than about 5 $\mathrm{mm}$. Second, since the acoustic theory can only deal with one crack, the design had to produce a single, isolated fatigue

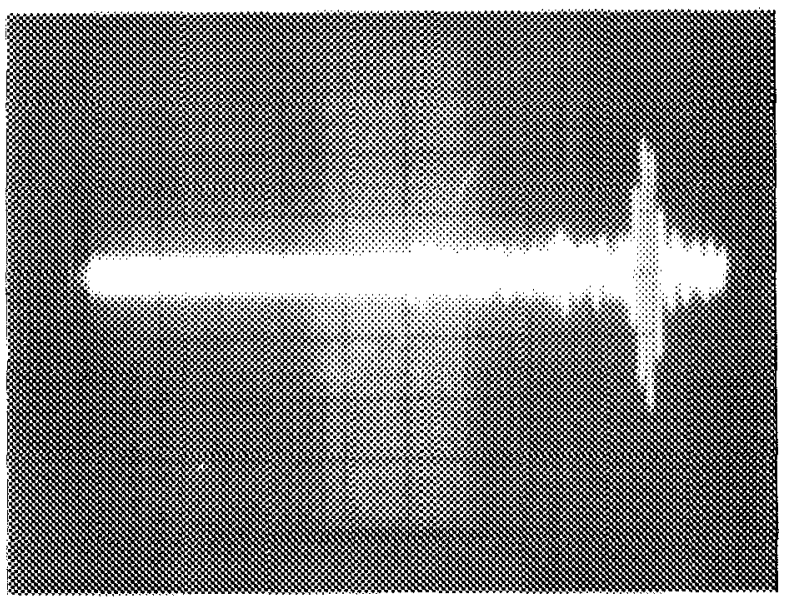

FIG. 4. Surface acoustic wave reflection signal from a small surface crack in a quenched and tempered 4140 steel sample under a stress slightly greater than that necessary for complete crack opening. Each horizontal division corresponds to $2 \mu$ s and each vertical division to $200 \mathrm{mV}$. 


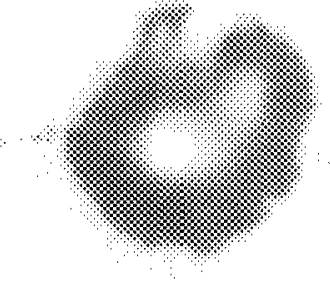

$25 \mathrm{~km}$

FIG. 5. Optical micrograph of a small surface crack initiated from the starter pit. The pit is located midway between the beveled edges shown in Fig. 3. The size of this crack is just greater than the minimum for detection by the surface acoustic wave technique. The loading axis is perpendicular to the crack plane.

crack. This crack needed to be naturally initiated, because cracks started artificially from large notches could show anomlous behavior due to the method of initiation. The overall size of the sample had to be small enough to fit into a typical scanning electron microscope (SEM) chamber for high magnification studies of the surface cracks. Finally, a well-characterized stress state was required.

The final sample design is shown in Fig. 3. The sample was loaded in cantilevered bending. All experiments were performed on a servohydraulic testing machine under $R=0$ loading conditions (i.e., zero-to-maximum tension loading). In order to localize the initiation site, a small pit $25 \mu \mathrm{m}$ in depth was produced on the specimen surface using an electro-spark machine with an extremely sharp, highly polished electrode. The pit is small enough for the crack to grow well away from its influence and to act as a naturally initiated crack, while still being within the crack depth regime capable of being monitored by the acoustic technique. The cross section of the sample at the throat was tapered, creating a uniform highly stressed central region, with the stress gradually decreasing to zero where the edges intersect the neutral axis. This served the dual purpose of further localizing the crack initiation region and preventing cracks from nucleating at the corners of a rectangular cross section.

\section{RESULTS AND DISCUSSION}

The sample design was found to be compatible with the SAW technique. No extra acoustic reflections that could possibly interfere with the crack signal were present. The reliability of acoustic signals from cracks in these samples (Fig. 4) was verified by correspondence to similar data taken on other specimens used to verify the accuracy of the technique. ${ }^{19-21}$

The small pit on the surface acted as an adequate initiation site for the surface cracks (Fig. 5). The number of cycles for crack initiation varied greatly from about 60000 to more than 300000 , at a maximum stress level of $70-78 \%$ of the yield stress. The large amount of scatter in the cycles re- quired for crack initiation is typical of high strength steel. ${ }^{24}$ No unwanted cracks formed on the specimen surface. Previous sample designs allowed multiple cracks to initiate or cracks initiated at corners, neither of which can be treated with the present acoustic theory.

The importance of the ability to study cracks which closely approximate naturally occurring ones lies in the nature of the initiated cracks. In previous studies with the acoustic technique ${ }^{19-21}$ small cracks were produced by creating a relatively large damaged area of several hundred microns on the surface, growing a crack from this area, and then machining away the damage leaving a surface crack of small dimensions. A crack so produced possesses a nonequilibrium aspect ratio. Upon subsequent growth the crack may show anomalous transient behavior in attaining its equilibrium $a / c$ value. Also, the effects of machining the surface containing the crack are not easily quantifiable. The new crack initiation technique described herein solves the above problems, allowing the study of more realistic small fatigue cracks.

\section{ACKNOWLEDGMENTS}

The author would like to thank Dr. A. D. Wilson of the Lukens Steel Company, Coatesville, Pennsylvania, for donating the steel used for this investigation and Dr. M. Resch, H. Yuce, Professor J. Shyne, and Professor D. Nelson for their technical discussions. The research was supported under a Department of Energy contract with Dr. Stanley Wolf as technical monitor. B. London is also supported by a fellowship from the Office of Naval Research.

${ }^{1} S$. Pearson, Eng. Fract. Mech. 7, 235 (1975).

${ }^{2}$ W. L. Morris, Metall. Trans. A 11A, 1117 (1980).

${ }^{3}$ A. K. Zurek, M. R. James, and W. L. Morris, Metall. Trans. A 14A, 1697 (1983).

${ }^{4} J$. Lankford, Fat. Eng. Mater. Struct. 5, 233 (1982).

${ }^{5}$ J. Lankford, Fat. Eng. Mater. Struct. (in press).

${ }^{6} \mathrm{~K}$. Tanaka, M. Hojo, and Y. Nakai, Fatigue Mechanisms: Advances in Quantitative Measurement of Physical Damage, ASTM STP 811 (American Society for Testing and Materials, Philadelphia, 1983), p. 207.

${ }^{7}$ D. Taylor and J. F. Knott, Fat. Eng. Mater. Struct. 4, 147 (1981).

${ }^{8}$ W. L. Morris, Metall. Trans. A 8A, 1079 (1977).

${ }^{9}$ W. L. Morris, Metall. Trans. A 8A, 1087 (1977)

${ }^{10}$ W. L. Morris, Metall. Trans. A 10A, 5 (1979).

"J. Lankford, Int. J. Fract. 16, R7 (1980).

${ }^{12}$ N. Dowling, Cyclic Stress-Strain and Plastic Deformation Aspects of Fatigue Crack Growth, ASTM STP 637 (American Society for Testing Materials, Philadelphia, 1977), p. 97.

${ }^{13}$ R. A. Smith, Int. J. Fract. 13, 717 (1977).

${ }^{14} \mathrm{~J}$. Lankford, Fat. Eng. Mater. Struct. 6, 15 (1983).

${ }^{15}$ S. Suresh, G. F. Zamiski, and R. O. Ritchie, Metall. Trans. A 12A, 1435 (1983).

${ }^{16} \mathrm{R}$. O. Ritchie and S. Suresh, Proceedings of the 55th Meeting of the AGARD Structural and Materials Panel on Behavior of Short Cracks in Airframe Components, Toronto, Canada, 1982.

${ }^{17}$ S. J. Hudak, Jr., J. Eng. Mater. Technol. 103, 26 (1981).

${ }^{18} \mathrm{~S}$. Suresh and R. O. Ritchie, Int. Metall. Rev. (in press).

${ }^{19}$ M. T. Resch, J. C. Shyne, G. S. Kino, and D. V. Nelson, Review of Progress in Quantitative Nondestructive Eualuation, edited by D. O. Thompson and D. E. Chimenti (Plenum, New York, 1982), Vol. 1, p. 573.

${ }^{20} \mathrm{M}$. T. Resch, D. V. Nelson, J. C. Shyne, and G. S. Kino, Advances in Crack Length Measurement, edited by C. J. Beevers (Engineering Materials Advisory Services, Ltd., West Midlands, England, 1983).

${ }^{2}$ M. T. Resch, Ph. D. thesis, Stanford University, Stanford, CA, 1982.

${ }^{22}$ G. S. Kino, J. Appl. Phys. 49, 3190 (1978).

${ }^{23}$ B. A. Auld, Wave Motion 1, 3 (1979).

${ }^{24}$ J. Lankford and F. N. Kusenberger, Metall. Trans. A 4A, 553 (1973). 